\title{
Moraxella bovis
}

National Cancer Institute

\section{Source}

National Cancer Institute. Moraxella bovis. NCI Thesaurus. Code C86524.

A species of aerobic, Gram negative, rod shaped, bacteria assigned to the phylum Proteobacteria. This species is oxidase positive, nonmotile, and requires serum or blood for growth in culture. M. bovis is pathogenic, being the causative agent of infectious bovine keratoconjunctivitis. However only the piliated variant can colonize the conjunctiva. 